\title{
Prediction of Motor Recovery after Stroke by Assessment of Corticospinal Tract Wallerian Degeneration Using Diffusion Tensor Imaging
}

\author{
Hoda Salah Darwish ${ }^{1}$ Rasha ElShafey ${ }^{2}$ Hanaa Kamel ${ }^{2}$ \\ ${ }^{1}$ Department of Radio-Diagnosis, Faculty of Medicine, Suez Canal \\ University, Ismailia, Egypt \\ ${ }^{2}$ Department of Radio-Diagnosis, Faculty of Medicine, Tanta \\ University, Tanta, Egypt

\begin{abstract}
Address for correspondence Hoda Salah Darwish, Assistant Professor, Dallah Hospital, Riyadh, P.O. BOX 87833 Riyadh, 11652 Saudi Arabia,

(e-mail: darwish.hoda.@yahoo.com).
\end{abstract}

Indian J Radiol Imaging 2021;31:131-137.

\begin{abstract}
Keywords

- corticospinal tract

- diffusion tensor imaging

- fractional anisotropy

- stroke

- Wallerian degeneration
\end{abstract}

Aim of the Study To predict motor recovery after stroke by detection of diffusion tensor imaging (DTI) fractional anisotropy (FA) changes of corticospinal tract (CST) and correlate findings with clinical scores to provide more effective treatment and rehabilitation.

Subjects and Methods Thirty patients with cerebral stroke were enrolled and underwent conventional magnetic resonance imaging and DTI at admission and 1 month after stroke. Mean diffusivity (MD), FA, FA ratio ( $r F A)$, and fiber number (FN) values of CST were calculated at the pons at admission and after 1 month of stroke. Three-dimensional reconstruction of bilateral CST and the structural changes of fibrous bands were observed. Severity of limb weakness was assessed by using the motor sub-index scores of the National Institutes of Health Stroke Scale (NIHSS) at admission, and after 1, 6, and 9 months for severity of limb weakness.

Results The mean age of our patients was $61.32 \pm 4.34$ years, $17 / 30(56.6 \%)$ were females, and 13/30 (43.4\%) were males. In our study, 18/30 (60\%) were hypertensive, $19 / 30(63.3 \%)$ were diabetic, and 12/30 (40\%) were smokers. A significant negative correlation was found between rFA and FN in the ipsilateral CST of the cerebral infarction at the rostral part of pons after 1 month of infarction and NIHSS score at 6 months ( $r=0.377, p=0.04$ and $r=0.237, p=0.02$, respectively). However, a positive insignificant correlation was found between MD and NIHSS $(r=0.345, p=0.635)$. The initial NIHSS score at the time of injury was $19.2 \pm 4.3$, which changed to $7.9 \pm 2.4,4.6 \pm 1.9$, and $3.3 \pm 1.4$ at 1,6 , and 9 months, respectively.

Conclusion DTI is a sensitive tool for early detection of Wallerian degeneration in the CST after stroke, and can predict motor performance to provide effective treatment and rehabilitation to improve quality of life. published online May 31, 2021
DOI https://doi.org/

10.1055/s-0041-1729671 ISSN 0971-3026
C 2021 . Indian Radiological Association
This is an open access article published by Thieme under the terms of the Creative
Commons Attribution-NonDerivative-NonCommercial-License, permitting copying
and reproduction so long as the original work is given appropriate credit. Contents
may not be used for commercial purposes, or adapted, remixed, transformed or
built upon. (https://creativecommons.org/licenses/by-nc-nd/4.0/).
Thieme Medical and Scientific Publishers Private Ltd. A-12, Second
Floor, Sector -2, NOIDA - 201301 , India 


\section{Introduction}

Ischemic cerebrovascular stroke is the second largest cause of death worldwide, and is defined as an episode of neurological dysfunction caused by focal cerebral, spinal, or retinal infarction. ${ }^{1,2}$

Motor deficit is one of the most common squeals of ischemic stroke, and its severity correlates with functional debility and reduced quality of life, and key for management and rehabilitation is its precise prediction.,4

The integrity of the motor fibers of the corticospinal tract (CST), which is the main pathway that transmits voluntary movements, mainly affects motor outcome.,

Wallerian degeneration (WD) is a phenomenon reflecting severe fiber tract damage of descending fiber tracts after ischemic stroke, which consists of the anterograde degeneration of axons and their myelin sheaths. ${ }^{7-9}$

It can occur as early as the first week postcerebral infarction, and presents as distal axonal swelling, rupture, collapse, and myelin relaxation at 1 week after onset. At 2 weeks after injury, myelin swelling, thickening, bending, and dissociation into free lipid and neutral fat were visible. ${ }^{10}$

WD represented as a change in signal intensities months or weeks after stroke along the affected CST on T2-weighted or diffusion-weighted imaging, and this correlates well with persistent functional disability. ${ }^{11,12}$

In the first few weeks after stroke, a conventional magnetic resonance imaging (MRI) will not show these subtle findings: ${ }^{13}$ however, diffusion tensor imaging (DTI) can provide information on the predominant direction and degree of tissue water diffusion..$^{14,15}$ It assesses the microstructural status of white matter objectively and quantitatively. ${ }^{16}$

DTI is a MRI sequence that specifically evaluates the directionality and integrity of brain axonal fibers and network strength in case of neuronal injury due to various etiologies including stroke. ${ }^{14}$

The integrity and the degree of organization of the fiber tracts within the brain are represented by the degree of anisotropy of diffusion. ${ }^{17}$

Reduced anisotropy along the CST remote from a cerebral infarction has been interpreted as WD, although these areas appeared normal on conventional MRI. ${ }^{18,19}$

DTI studies have established fractional anisotropy (FA) values as surrogate markers of motor deficit after stroke: worse motor function usually relates to lower values in affected CST. 13,20,21

The aim of this study was to predict motor recovery after stroke by detection of DTI FA changes of CST and correlate findings with clinical scores to provide more effective treatment and rehabilitation.

\section{Subjects and Methods}

Prospectively a total number of 30 patients referred to the Radiology Department from the Neurovascular Unit, intensive care units of the Neurology Department, and the Center of Neurology and Psychiatry, Tanta University Hospitals, with variable degrees of neurological manifestations from July 2017 to April 2018 were included in our study.

The study's protocol was approved by the Research Ethics Committee and Quality Assurance Unit, Faculty of Medicine, Tanta University. Participations were voluntary, and informed consents were obtained from all included patients and the possible risks were clarified.

\section{Exclusion Criteria}

Exclusion criteria were contraindications for MRI, infratentorial lesions, recurrence of infarction during 9 months of follow-up, other causes of limb weakness, and neurodegenerative diseases. Vitally unstable patients and those with advanced renal, hepatic, chest, or cardiac diseases were also excluded.

\section{Clinical Assessment}

Patients were submitted to history taking, complete neurological examination, and stroke severity assessment using the National Institutes of Health Stroke Scale (NIHSS) by a certified neurologist at admission, and after 1, 6, and 9 months after stroke onset. The neurologists evaluated the NIHSS by examining 11 parts, with 13 specific tests. The NIHSS examines for level of consciousness, vision and gaze, facial palsy and extremity weakness, limb ataxia, sensory loss, language and dysarthria, and neglect. It is designed to be conducted over 7 minutes.

A patient with a completely normal neurological exam and normal mental status will have an NIHSS of 0 . The maximum recordable NIHSS score is 42 : $0-15$ mild stroke, 15-22 moderate stroke, and 22-42 severe stroke. ${ }^{22}$

Brain MRI was done at admission and 1 month after stroke to all our included patients at the MRI unit at the Radio Diagnosis and Medical Imaging Department, Tanta University Hospital using GE Healthcare, Milwaukee, Wisconsin, United States. The images were attained by a 1.5-Tesla, General Electric Scanner (GE Medical Systems, Milwaukee, United States) with quadrature 8-channel head coil included with axial T1- and T2-weighted fast spin-echo, three-dimensional (3D) FLAIR, and diffusion-weighted images using strong gradient strength [high $b$-values $\left.=1,000 \mathrm{~s} / \mathrm{mm}^{2}\right]$ with estimation of the associated apparent diffusion coefficient value.

Corticospinal diffusion tensor tractography was done at the time of admission and 1 month after onset of stroke to measure the FA, mean diffusivity (MD), and fiber number (FN) in the region of abnormality compared with the contralateral hemisphere.

The DTI sequence consisted of single-shot spin echo-planar imaging with the following parameters: $\mathrm{TR}=8,830 \mathrm{~ms}$; $\mathrm{TE}=$ $80 \mathrm{~ms}$; acquisition matrix $=112 \times 110 \mathrm{~mm}$; acquisition voxel $=2.00 / 2.03 / 2.00 \mathrm{~mm}$; FOV: right-left $=224 \mathrm{~mm}$, anteroposterior $=224 \mathrm{~mm}$, feet-head $=120 \mathrm{~mm}$; voxel size: right-left $=2 \mathrm{~mm}$, anteroposterior $=2 \mathrm{~mm}$, slice thickness $=2 \mathrm{~mm}$, reconstruction voxel size $=1.75 \mathrm{~mm}$, gradient direction $=32$, $b$-value $=800 \mathrm{~mm} / \mathrm{s}$, and number of slices $=60$. Total scan time was 9:51 minutes. 
The DTIs were transferred to the work station (advantage window 4.7), where they were converted to color-coded map images, 3D tract reconstruction, FA map, and MD map.

Patients continued a follow-up schedule for 1,6 , and 9 months for severity of limb weakness assessed by using the motor sub-index scores of the NIHSS.

Statistical analysis of the present study was conducted using the mean and standard deviation by SPSS V.16. Analysis of variance (ANOVA) tests and Tukey's test were used to determine the significance between two groups, according to the computer program SPSS for Windows. The ANOVA test was used for comparison among different times in the same group in quantitative data. A $p$-value $<0.05$ was considered significant.

Correlations were made among MD, FA, rFA and FN, and NIHSS scores by using the Spearman rank correlation test.

\section{Results}

Thirty consecutive patients with supratentorial ischemic stroke were included in the study. The baseline evaluation of the included 30 patients showed that their mean age was $61.32 \pm 4.34$ years, $17 / 30$ (56.6\%) were females and $13 / 30$ (43.4\%) were males.

In our study, 18/30 (60\%) were hypertensive, 19/30 (63.3\%) were diabetic, and 12/30 (40\%) were smokers.

The result of the present study showed that right-sided brain infraction was seen in 19 patients (63\%), while left-sided infarction was seen in 11 patients (27\%). The regions involved with infarct were as follows: temporal infraction: 11 cases (37\%), striatocapsular infarction: 7 cases (23\%), parietal infarction: 5 (17\%), tempro-parieto-occipital infarction: 2 cases (1\%), and thalamic infarction: 5 cases (17\%).
Table 1 Different locations of CST damage and infarction volume

\begin{tabular}{|l|l|l|}
\hline & At admission & $\begin{array}{l}\text { After 1 } \\
\text { month }\end{array}$ \\
\hline Location of CST damage & $\mathbf{2 h}(\boldsymbol{n}=\mathbf{3 0 )}$ & $(\boldsymbol{n}=\mathbf{3 0})$ \\
\hline Motor cortex & 4 & \\
\hline Premotor cortex & 8 & 3 \\
\hline Corona radiate & 5 & 9 \\
\hline PLIC & 5 & 2 \\
\hline Centrum semiovale & 4 & 5 \\
\hline $\begin{array}{l}\text { Infarction volume }\left(\mathrm{mm}^{3}\right) \\
\text { (mean + SD) }\end{array}$ & $17 \pm 2.7$ & 5 \\
\hline
\end{tabular}

Abbreviations: CST, corticospinal tract; PLIC, posterior limb of the internal capsule; SD, standard deviation.

At the time of admission the CST integrity was disrupted in 26 cases and preserved in 4 cases, while after 1 month 6 cases revealed intact CST ( - Table $\mathbf{1}$ ).

The result showed that mean FA values of the ipsilateral CST at the pons were significantly different from those on the normal contralateral side only after 1 month $(p<0.001)$, with decreased mean FA values on the affected side after 1 month compared with those at admission time ( - Table 2 and -Figs. 1-3).

A significant negative correlation was found in moderate and severe motor deficit between rFA and FN in the ipsilateral CST at the rostral part of pons after 1 month of infarction and NIHSS score at 6 months, $r=0.377(p=0.04)$ and $r=0.237$ $(p=0.02)$, respectively, while an insignificant correlation was found in mild motor deficit (-Table 2 ).

Table 2 Relation between grades of motor score (NIHSS) and different DTI parameters

\begin{tabular}{|c|c|c|c|c|c|c|c|c|}
\hline \multirow{2}{*}{$\begin{array}{l}\text { NIHSS } \\
\text { grade }\end{array}$} & \multicolumn{2}{|c|}{ FA } & \multicolumn{2}{|c|}{ rFA } & \multicolumn{2}{|c|}{$\operatorname{MD}\left(10^{3}\right)$} & \multicolumn{2}{|r|}{ FN } \\
\hline & $\begin{array}{l}\text { At } \\
\text { admission }\end{array}$ & $\begin{array}{l}\text { After } 1 \\
\text { month }\end{array}$ & $\begin{array}{l}\text { At } \\
\text { admission }\end{array}$ & $\begin{array}{l}\text { After } 1 \\
\text { month }\end{array}$ & $\begin{array}{l}\text { At } \\
\text { admission }\end{array}$ & $\begin{array}{l}\text { After } 1 \\
\text { month }\end{array}$ & $\begin{array}{l}\text { At } \\
\text { admission }\end{array}$ & After 1 month \\
\hline \multirow[t]{4}{*}{ Mild } & Ipsilateral & Ipsilateral & $0.9+0.08$ & $0.8+0.07$ & Ipsilateral & Ipsilateral & Ipsilateral & Ipsilateral \\
\hline & $0.62 \pm 0.08$ & $0.59+0.04$ & & & $0.74 \pm 0.04$ & $0.77 \pm 0.03$ & $150 \pm 20$ & $142 \pm 14$ \\
\hline & Contralateral & Contralateral & & & Contralateral & Contralateral & Contralateral & Contralateral \\
\hline & $0.65 \pm 0.07$ & $0.64 \pm 0.08$ & & & $0.84 \pm 0.08$ & $0.84 \pm 0.07$ & $152 \pm 26$ & $151 \pm 24$ \\
\hline \multirow[t]{4}{*}{ Moderate } & Ipsilateral & Ipsilateral & $0.9+0.06$ & $0.77+0.05$ & Ipsilateral & Ipsilateral & Ipsilateral & Ipsilateral \\
\hline & $0.59 \pm 0.07$ & $0.52 \pm 0.04$ & & & $0.73 \pm 0.06$ & $0.78 \pm 0.07$ & $148 \pm 23$ & $131 \pm 10$ \\
\hline & Contralateral & Contralateral & & & Contralateral & Contralateral & Contralateral & Contralateral \\
\hline & $0.64+0.06$ & $0.64+0.08$ & & & $0.88 \pm 0.08$ & $0.88 \pm 0.06$ & $152 \pm 24$ & $148 \pm 27$ \\
\hline \multirow[t]{4}{*}{ Severe } & Ipsilateral & Ipsilateral & $0.8+0.09$ & $0.72+0.02$ & Ipsilateral & Ipsilateral & Ipsilateral & Ipsilateral \\
\hline & $0.59 \pm 0.04$ & $0.48 \pm 0.03$ & & & $0.74 \pm 0.03$ & $0.81 \pm 0.06$ & $148 \pm 21$ & $122 \pm 18$ \\
\hline & Contralateral & Contralateral & & & Contralateral & Contralateral & Contralateral & Contralateral \\
\hline & $0.61+0.08$ & $0.58+0.06$ & & & $0.83 \pm 0.07$ & $0.86 \pm 0.09$ & $152 \pm 21$ & $147 \pm 19$ \\
\hline
\end{tabular}

Abbreviations: FA, fractional anisotropy; FN, fiber number; MD, mean diffusivity; NIHSS, National Institute of Health Stroke Scale; rFA, fractional anisotropy ratio. 

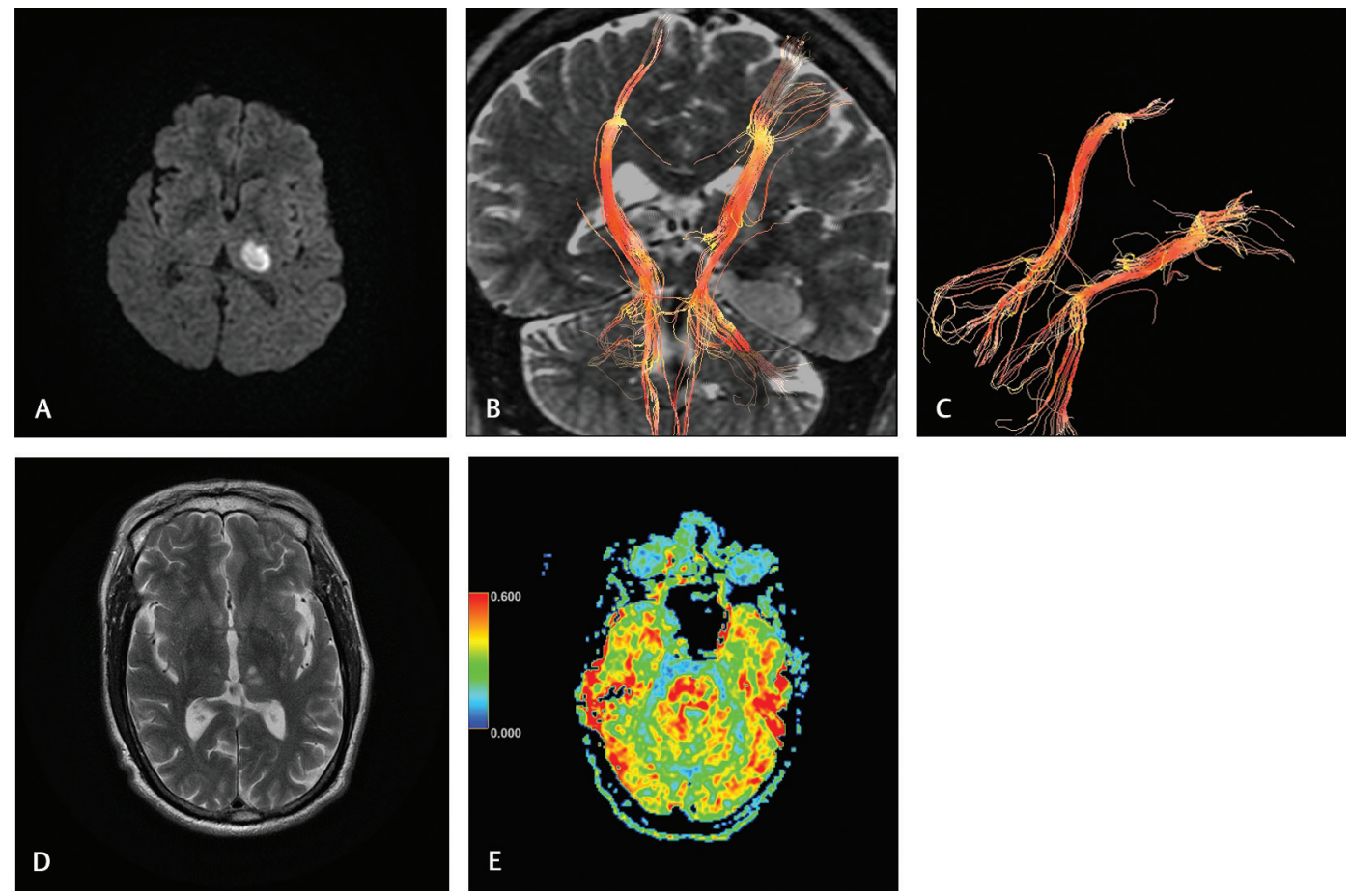

Fig. 1 (A-E) Case 1: A 65-year-old male presented with right hemiparesis (NIHSS, 9). Imaging at 16 hours of stroke: (A) diffusion-weighted image reveals acute left thalamic acute infarction (PCA territory). (B and C) 3D reconstruction of corticospinal tract reveals mild attenuation of the left CST with decreased fiber number, minimal compression, and shifting. Imaging at 30 days of stroke: (D) axial T2-weighted image reveals a decrease in the size and intensity of infarction. (E) Axial FA map at the pons reveals decreased FA at the left side (rFA: 0.94) denoting Wallerian degeneration. CST, corticospinal tract; FA, fractional anisotropy; NIHSS, National Institute of Health Stroke Scale; rFA, fractional anisotropy ratio.
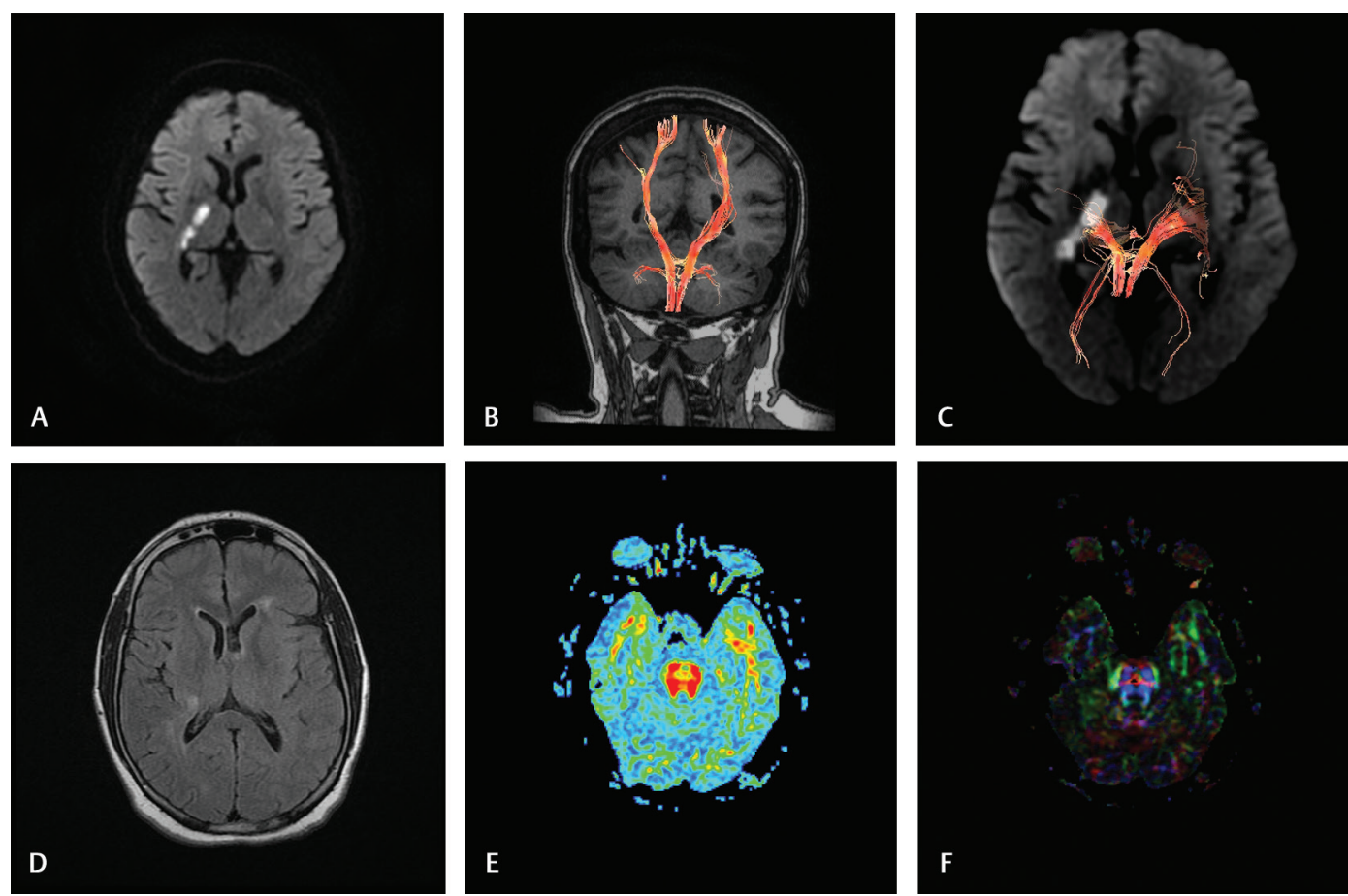

Fig. 2 (A-F) Case 2: A 53-year-old female presented with left hemiparesis (NIHSS,4). Imaging at 8 hours of stroke: (A) diffusion-weighted image reveals acute infarction at right posterior limb of internal capsule. (B and C) 3D reconstruction of corticospinal tract reveals minimal attenuation of the right CST with decreased fiber number. Imaging at 30 days of stroke: (D) axial FLAIR-weighted image reveals a decrease in the size and intensity of infarction. (E) Axial FA map at the pons reveals normal FA on both sides (rFA: 1.01) denoting no obvious Wallerian degeneration. (F) Color-coded map at the pons reveals normal both CST at the rostral part. CST, corticospinal tract; FA, fractional anisotropy; NIHSS, National Institute of Health Stroke Scale; rFA, fractional anisotropy ratio. 

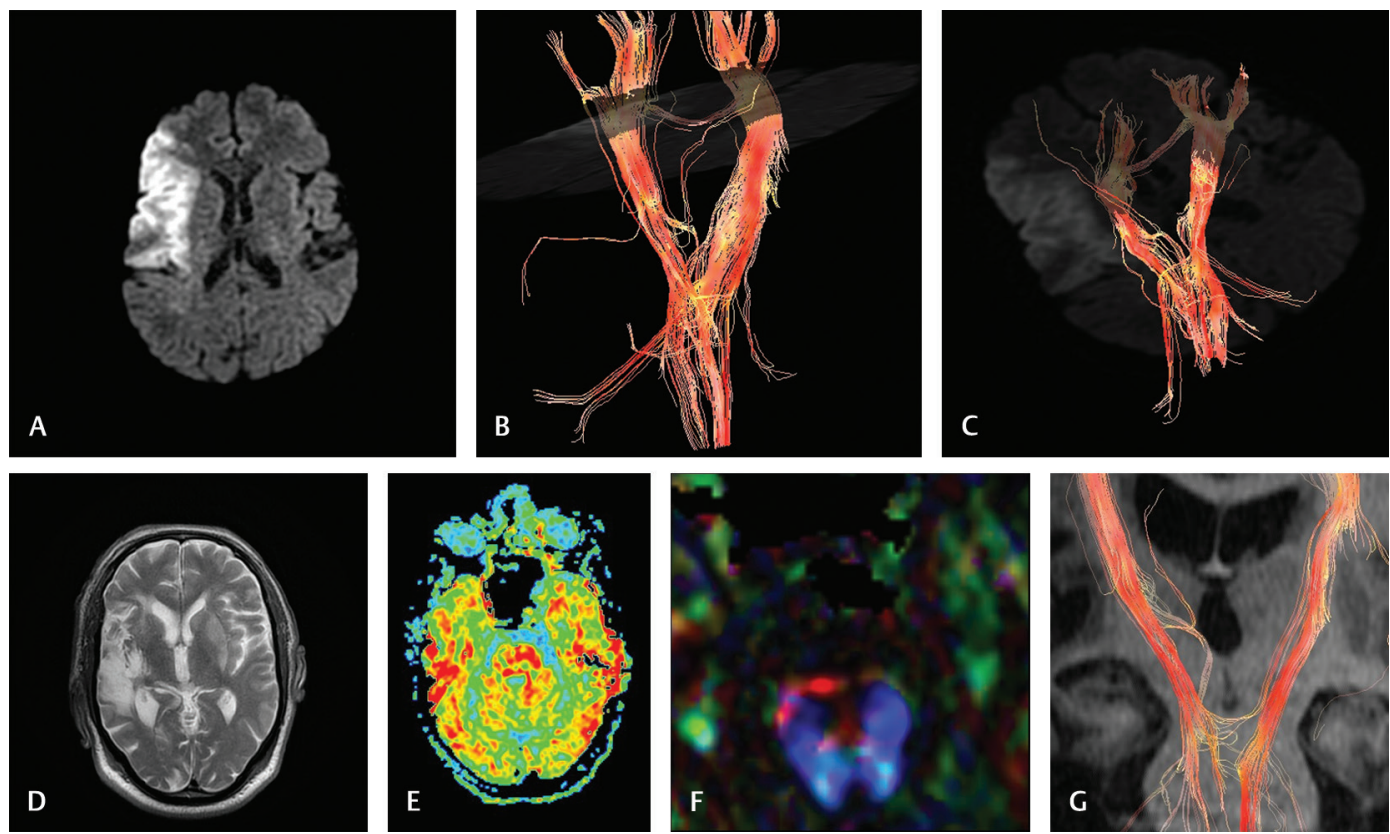

Fig. 3 (A-G) Case 3: A 64-year-old male with left-sided hemiplegia (NIHSS19). Imaging at 10 hours of stroke: (A) diffusion-weighted image reveals right temporal acute infarction. (B and C) 3D reconstruction of corticospinal tract reveals displacement, mild attenuation, interruption at the motor cortex and corona radiata, decreased fiber number of ipsilateral CST. Imaging at 30 days of stroke: (D) axial T2 WI reveals a decrease in the size and intensity of infarction. (E) Axial FA map at the pons reveals a marked decrease in FA on the right side (rFA: 0.83) denoting Wallerian degeneration. (F) Color-coded map at the pons reveals distortion of right CST. (G) 3D reconstruction of both CSTs reveals attenuation and a decreased number of fiber of CST at the pons denoting Wallerian degeneration. CST, corticospinal tract; FA, fractional anisotropy; NIHSS, National Institute of Health Stroke Scale; rFA, fractional anisotropy ratio; WI, weighted image.

A positive insignificant correlation was found between MD and NIHSS ( $r=0.345, p=0.635)$.

The initial NIHSS score at the time of injury was $19.2 \pm 4.3$, which changed to $7.9 \pm 2.4,4.6 \pm 1.9$, and $3.3 \pm 1.4$ at 1,6 , and 9 months, respectively ( - Table 3 ).

\section{Discussion}

Poststroke motor deficit has a huge influence on quality of life. ${ }^{23,24}$ Precise early anticipation of motor functional outcome in the early stage of stroke is crucial in management and rehabilitation. ${ }^{25}$ Tissue edema and mass effect may be responsible for increased motor deficit in early poststroke period which makes reliability on clinically based biomarkers imprecise and needs additional neuroimaging tools to assess corticospinal, neurophysiological, and structural integrity. ${ }^{26}$

Regarding patients' age, in our study the mean age of our patients was $61.32 \pm 4.34$ years, these results are in accordance with the work of Torrealba-Acosta et al, ${ }^{27}$ who found that an advanced age is a nonmodifiable risk factor for ischemic stroke associated with higher morbidity and mortality rates. On the other hand, these results are not in harmony with the work of Cai et $\mathrm{al}^{28}$ who concluded that the age per se is not a bad prognostic factor, but the age-related vascular risks including hypertension, diabetes, and cardiovascular diseases are the cause of poor functional outcome after stroke.

In our study, we tried to determine whether the detection of WD of CST after 1 month of stroke can predict motor performance of the patient and if it can be used as prognostic
Table 3 Changes over time of NIHSS score

\begin{tabular}{|l|l|}
\hline Time & NIHSS (mean + SD) \\
\hline At admission & $19.2 \pm 4.3$ \\
\hline After 1 month & $7.9 \pm 2.4$ \\
\hline After 6 months & $4.6 \pm 1.9$ \\
\hline After 9 months & $3.3 \pm 1.4$ \\
\hline
\end{tabular}

Abbreviations: NIHSS, National Institute of Health Stroke Scale; SD, standard deviation.

markers for the course of the disease aiming to enhance quality of care and life.

DTI is a new MRI technique that enables quantitative estimation of tissue microstructure based on diffusivity properties of Brownian water molecule motions, which makes it able to reconstruct a 3D macroscopic orientation and to visualize the integrity of white matter tracts at the infarcted area and so anticipate the degree of motor recovery. ${ }^{29}$

The acuteness of motor impairments correlates with functional disability and patient quality of life and there is high interindividual variability in recovery for patients with initially moderate-to-severe impairment. From our study, the merit of DTI in stroke patients is accurate early prediction of recovery, which would help rationalize rehabilitation goals and improve the design of trial-testing strategies to facilitate recovery.

Results of our study that are confirmed by other studies $^{7,9,18}$ show that imaging-based regional markers associate with motor deficits in stroke patients and when we were correlating DTI findings with clinical data, we found that 
motor deficits 30 days after stroke enlarged with reduced anisotropy in the pons, and the decrease in the FA values in the affected CST becomes progressively minute during the subacute-to-chronic stages of stroke.

In our study, we found that the signal strength altered in the affected CST was strongly associated with lower FA indexes. These findings advocate that DTI is more receptive in detecting tissue changes regarded as WD.

Some authors reported that greater FA reduction along the CST on the injured side postcerebral infarction is associated with greater early motor deficit and worse motor recovery at 3 months. ${ }^{20,30}$

We found significant correlations between FA indexes and motor deficit only at 30 days, and the reductions in mean FA is approximately $11 \%$, which are similar to other published values measured at the pons. ${ }^{19,31}$

Combining clinical scores with information about CST integrity can improve prediction about motor outcome. The extent of CST damage on DTI and/or overlap between the CST and a lesion are key prognostic factors that determine motor performance and outcome.

Limitations of our study include the following: first, the small number of patients with motor deficits at 30 days; second, manual region-of-interest placement is subject to operator bias, especially after 1 month, when CST damage is present, and this may result in variability in location, size, and shape.

Further studies with larger samples and using automated region-of-interest analysis or voxel-based analysis will increase the power of our findings.

\section{Recommendation}

We recommend adding the quantitative DTI to the other routine sequences for diagnosis and follow-up of stroke patients. We also recommend other long-standing studies for evaluation of using DTI for monitoring treatment response.

\section{Conclusion}

Diffusion tensor imaging is a sensitive tool for early detection of Wallerian degeneration in the corticospinal tract after stroke, and can predict motor performance and outcome to provide more effective treatment and rehabilitation and improve quality of life.

From our study we conclude that the decrease of corticospinal tract fractional anisotropy after 1 month correlates positively with the motor deficit 1 and 6 months after stroke.

\section{Financial Support and Sponsorship \\ Nil.}

\section{Conflicts of Interest}

There are no conflicts of interest.

\section{References}

1 Feigin VL, Norrving B, Mensah GA. Global burden of stroke. Circ Res 2017;120(3):439-448
2 Sacco RL, Kasner SE, Broderick JP, et al; American Heart Association Stroke Council, Council on Cardiovascular Surgery and AnesthesiaCouncil on Cardiovascular Radiology and InterventionCouncil on Cardiovascular and Stroke NursingCouncil on Epidemiology and PreventionCouncil on Peripheral Vascular DiseaseCouncil on Nutrition, Physical Activity and Metabolism. An updated definition of stroke for the 21st century: a statement for healthcare professionals from the American Heart Association/American Stroke Association. Stroke 2013;44(7):2064-2089

3 Duncan PW, Goldstein LB, Matchar D, Divine GW, Feussner J. Measurement of motor recovery after stroke. Outcome assessment and sample size requirements. Stroke 1992;23(8):1084-1089

4 Coupar F, Pollock A, Rowe P, Weir C, Langhorne P. Predictors of upper limb recovery after stroke: a systematic review and meta-analysis. Clin Rehabil 2012;26(4):291-313

5 Schiemanck SK, Kwakkel G, Post MW, Kappelle LJ, Prevo AJ. Impact of internal capsule lesions on outcome of motor hand function at one year post-stroke. J Rehabil Med 2008;40(2):96-101

6 van Kuijk AA, Pasman JW, Hendricks HT, Zwarts MJ, Geurts AC. Predicting hand motor recovery in severe stroke: the role of motor evoked potentials in relation to early clinical assessment. Neurorehabil Neural Repair 2009;23(1):45-51

7 Johnson AC, McNABB AR, Rossiter RJ. Chemistry of wallerian degeneration; a review of recent studies. Arch Neurol Psychiatry 1950;64(1):105-121

8 Iizuka H, Sakatani K, Young W. Corticofugal axonal degeneration in rats after middle cerebral artery occlusion. Stroke 1989;20(10):1396-1402

9 Kuhn MJ, Mikulis DJ, Ayoub DM, Kosofsky BE, Davis KR, Taveras JM. Wallerian degeneration after cerebral infarction: evaluation with sequential MR imaging. Radiology 1989;172(1):179-182

10 Uchino A, Sawada A, Takase Y, Egashira R, Kudo S. Transient detection of early wallerian degeneration on diffusion-weighted MRI after an acute cerebrovascular accident. Neuroradiology 2004;46(3):183-188

11 Kang DW, Chu K, Yoon BW, Song IC, Chang KH, Roh JK. Diffusion-weighted imaging in Wallerian degeneration. J Neurol Sci 2000;178(2):167-169

12 Castillo M, Mukherji SK. Early abnormalities related to postinfarction Wallerian degeneration: evaluation with MR diffusion-weighted imaging. J Comput Assist Tomogr 1999;23(6):1004-1007

13 Puig J, Pedraza S, Blasco G, et al. Wallerian degeneration in the corticospinal tract evaluated by diffusion tensor imaging correlates with motor deficit 30 days after middle cerebral artery ischemic stroke. AJNR Am J Neuroradiol 2010;31(7):1324-1330

14 Puig J, Blasco G, Schlaug G, et al. Diffusion tensor imaging as a prognostic biomarker for motor recovery and rehabilitation after stroke. Neuroradiology 2017;59(4):343-351

15 Mukherjee P, Chung SW, Berman JI, Hess CP, Henry RG. Diffusion tensor MR imaging and fiber tractography: technical considerations. AJNR Am J Neuroradiol 2008;29(5):843-852

16 Nucifora PG, Verma R, Lee SK, Melhem ER. Diffusion-tensor MR imaging and tractography: exploring brain microstructure and connectivity. Radiology 2007;245(2):367-384

17 Beaulieu C. The basis of anisotropic water diffusion in the nervous system - a technical review. NMR Biomed 2002;15(7-8):435-455

18 Thomalla G, Glauche V, Koch MA, Beaulieu C, Weiller C, Röther J. Diffusion tensor imaging detects early Wallerian degeneration of the pyramidal tract after ischemic stroke. Neuroimage 2004;22(4):1767-1774

19 Werring DJ, Toosy AT, Clark CA, et al. Diffusion tensor imaging can detect and quantify corticospinal tract degeneration after stroke. J Neurol Neurosurg Psychiatry 2000;69(2):269-272 
20 Thomalla G, Glauche V, Weiller C, Röther J. Time course of wallerian degeneration after ischaemic stroke revealed by diffusion tensor imaging. J Neurol Neurosurg Psychiatry 2005;76(2):266-268

21 Lindenberg R, Zhu LL, Rüber T, Schlaug G. Predicting functional motor potential in chronic stroke patients using diffusion tensor imaging. Hum Brain Mapp 2012;33(5):1040-1051

22 Kasner SE. Clinical interpretation and use of stroke scales. Lancet Neurol 2006;5(7):603-612

23 Mori S, Crain BJ, Chacko VP. van Zijl PC. Three-dimensional tracking of axonal projections in the brain by magnetic resonance imaging. Ann Neurol 1999;45(2):265-269

24 Shelton FD, Volpe BT, Reding M. Motor impairment as a predictor of functional recovery and guide to rehabilitation treatment after stroke. Neurorehabil Neural Repair 2001;15(3):229-237

25 Hendricks HT, van Limbeek J, Geurts AC, Zwarts MJ. Motor recovery after stroke: a systematic review of the literature. Arch Phys Med Rehabil 2002;83(11):1629-1637

26 Lin CC, Tsai MY, Lo YC, et al. Reproducibility of corticospinal diffusion tensor tractography in normal subjects and hemiparetic stroke patients. Eur J Radiol 2013;82(10):e610-e616
27 Torrealba-Acosta G, Carazo-Céspedes K, Chiou SH, O’Brien AT, Fernández-Morales H. Epidemiology of stroke in Costa Rica: a 7-year hospital-based acute stroke registry of 1319 consecutive patients. J Stroke Cerebrovasc Dis 2018; 27(5):1143-1152

28 Cai Z, He W, Peng CY, Zhou J, Xu QL, Wu ZS. The prevalence of lacunar infarct decreases with aging in the elderly: a case-controlled analysis. Clin Interv Aging 2016;11:733-738

29 Dubey P, Lioutas VA, Bhadelia R, et al. Quantitative microstructural deficits in chronic phase of stroke with small volume infarcts: a diffusion tensor 3-D tractographic analysis. Magn Reson Imaging 2016;34(5):662-667

30 Liang Z, Zeng J, Zhang C, et al. Longitudinal investigations on the anterograde and retrograde degeneration in the pyramidal tract following pontine infarction with diffusion tensor imaging. Cerebrovasc Dis 2008;25(3):209-216

31 Pierpaoli C, Barnett A, Pajevic S, et al. Water diffusion changes in Wallerian degeneration and their dependence on white matter architecture. Neuroimage 2001;13(6, Pt 1) :1174-1185 